\title{
The Impacts of the Cooperation among Physical Education Teachers and Parents into Improving the Quality of the Students' Acquisition and Education Achievements
}

\author{
Prof. Asoc. Dr. Ardian Shingjergji \\ Faculty of Education Sciences, "Aleksandër Xhuvani" University of Elbasan \\ Email address: ardianshingjergji@gmail.com
}

\author{
Doi:10.5901/ajis.2016.v5n3s1p110
}

\begin{abstract}
Nowadays, the need to involve parental community into the instruction and education processes in our schools is becoming more and more important, due even to the fact that partnering and collaboration lay into the foundations of the teachers and parents' activity. In these terms, this writing is treating issues connected with information and theoretical concepts of parental involvement into the instruction and education processes, the role of the teacher in general and particularly the role of the physical education teachers, the strategies to be used for being as much effective and qualitative as possible as well as expectations from this collaboration. Writing methodology is based on researching contemporary bibliography as well as on compiling and using questionnaires to the high school physical education teachers of Elbasan town, by means of which it has been intended to present the tableau of parental involvement in education as well as in the school community in general as genuinely as possible.
\end{abstract}

Keywords: Involvement, cooperation, strategy, expectation, teachers, parents, education.

\section{Introduction}

The need to be informed about and aware of their children's progress and achievement at school as well as in other leisure activities is one of parents' core expectation. They should enjoy the right to get involved in discussions and be part of the decision-making process for issues related to their children. The ways children are activated and involved in the teaching-learning process, assessment of the potentials they own, the strong and weak points, difficulties and problems they are being faced with in various subjects, the ways teachers use to make possible students to be attentive to what is going on in their school life, the ways students enter into relationships with their teachers as well as with their coevals/classmates, the ambiance associating children in their classrooms, school, etc, are some of the issues that should be involved in the information for parents. Children and the school can be considered as two important poles in the social life, in which, both parents and teachers intend the best achievements for children. However, there might be cases when the regular and systematic collaboration lacks and tensions and misunderstandings might result among teachers and parents in their ways of thinking, acting as well as in their attitudes to different issues.

\section{Theoretical Insights}

\subsection{Parental Involvement}

Researchers have once commented that the parental role in child education should centre only in choosing the school, creating the proper ambiance at home for the social and emotional development of children as well as for the formation of their moral values.

Some used to say that parents have nothing to do with the children progress at school but others would contradict it as an outdated point of view regarding the parental (non) involvement at school life which is irreconcilable with the terms of present-day perceptions regarding the issue.

Parental involvement now means so much for parents that presently they consider it as a family necessity for the children's progress at school. The greatest part of the contemporary literature keeps suggesting that parents' involvement is helpful in the following directions; enhances and increases the children's progress at school, produces better scores in tests, improves behaviour and morale, has a positive impact in parents-children relationships, increases caring to children, etc. 
Findings from all research have been affecting parental involvement to a great extend and other efforts are being made to reveal the best methods to this approach, despite obstacles encountered. One of the problems encountered in parental involvement are the different ways the issue has been perceived by teachers and parents; culture is a variable that can change their ideas about the most effective ways parents should be involved in the life of the school.

In present-day perception parental involvement has been considered in two categories; their involvement at home and at school.

Home involvement has been defined by Sheldon (2002), as interaction of parents with their children regarding issues related to learning process (the school), as well as in other learning activities and it represents the direct investment of parents' resources in the education of their children.

The second kind of parental involvement, the one occurring at school, includes voluntarism and parents' gatherings with the school community to get informed about their children's progress.

\subsection{Strategies to further increase parental involvement.}

Many strategies of increasing parental involvement have emerged as a result of efforts to get over obstacles encountered to this regard. One of the ways to achieve this is raising people's awareness about the benefits of parental involvement and the application of the most successful methods and models for this approach. According to Karther and Lowden, (1997), there are several ways to reveal and test the best parental involvement measures for families at risk. Informal gatherings with families at the beginning of the school year, regular contacts of school with families by means of the teachers in charge of respective classes, school and leisure activities initiated particularly by the physical education and sport teachers as well as phoning families and in most cases writing positively about students' behaviour than negatively.

Homeless families should also be considered as vulnerable as families at risk; school and teachers should care to secure a welcoming ambiance for parents from these families, too. Certain researchers suggest several ways of involving parents among which we can mention the following; making a reception room available for parents, reception manual, appointing special days for parents and students, home visits, official notifications for parents, the protocol of parentteacher meetings as well as a welcoming programme for new students and their parents.

Various schools and states are attempting to increase parental involvement by educating teachers to this regard in order to be successful in fulfilling their duties. To serve to this aim, parental involvement has become part of the school curricula via "interactive homework". 'Interactive homework" is based on a concept developed by Balli (1996), aiming to involve and further engage parents in resolving wants and assignments school requires from their children.

\subsection{Parental expectations}

Another aspect of parental involvement is parental expectations. In their study, authors Fan and Chen (2001), discovered a significant relationship between the parental involvement and academic achievements; moreover, they discovered an even stronger relationship among parental involvement and their expectations.

However, researchers emphasize that parents' expectations should be identified in time and communicated to the school community. Trivette, Anderson, et al.(1995), asserted that these expectations are, in most cases communicated by verbal communication to the school and on regular bases. Surprisingly, these high expectations did not result to have direct effect in the family structural changes in the course of interaction with school or in higher levels of participation in school activities.

The highest expectations, though, exert an indirect influence on both these aspects of parental involvement. Higher parental expectation can indirectly influence over these two aspects of parental involvement. Parental expectations can influence strongly on the children's school performance. In cases when parents have higher expectations, children's progress is optimal. This kind of relationship is maintained even in cases when the effects of the factors like the social and economic status are considered.

\section{Methodology}

Realization of this study was based on the selection of native and foreign theoretical materials regarding issue linked with the role of the (physical education) teachers for parental involvement in the teaching and education processes.

Collection of the study data was done by means of questionnaires distributed to five high schools of Elbasan Town, respectively in public schools "Dhaskal Todri", "Kostandin Kristoforidhi", "Vasil Kamami", "Mahir Domi" as well as in the 
private school "Nickolas Copernicus". Questionnaires were drafted to get response by 20 physical education teachers. Canvassing was completed in the period March-April 2016. The questions used in the questionnaires are the following;

1. Does parents' participation serve for a better school?

2. Do parents know how to help children with their school assignments or any other activities of physical character they have to perform at home?

3. Have families the proper commitment to enhance students for yielding better results at school?

4. Are parents prone to learn proper methods and techniques for helping their children at home?

5. Does the parental collaboration and involvement increase the affectivity of the teachers' work at school?

6. To what extent is teachers- parents consulting significant in the teaching-learning process?

7. To what extent is voluntarism important for the parents-teachers involvement?

\section{Outcomes and the Discourse}

While responding to the question whether parents' participation served to have a better school, the data collected revealed that $97 \%$ of teachers agree strongly whereas the remaining $3 \%$ simply agree which shows that teachers consider parents' participation and involvement very significant for this approach.

\section{Graph 1}

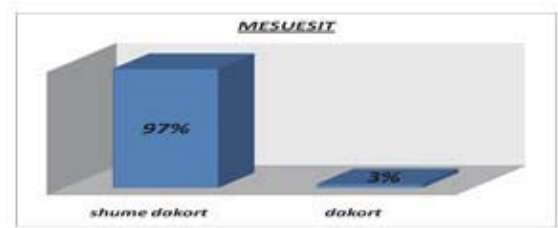

Results obtained from the second question show that $57 \%$ of the teachers state that parents know how to help their children whilst $38 \%$ state that parents can fairly help their children related to school assignments and other activities of physical character in home conditions whereas $5 \%$ of the responders think that parents do not have proper and contemporary knowledge to this regard. In general, these data are way too positive since they affect not only children's academic development but even their emotional development. They also reveal the need for continuous qualification as well as updating parents with proper cognition to increase the effectiveness of the teachers and the school work in education.

\section{Graph 2}

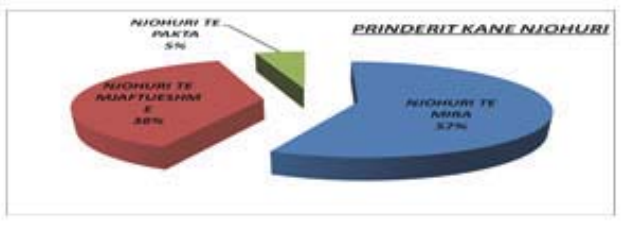

Regarding the importance of the family in positive enhancement of students to reach better results at school the results showed that $36 \%$ of the teachers fairly agree, $44 \%$ agree and $20 \%$ strongly agree; these data makes us reflect in relation to the work of many researchers which connect positive achievements of their students with the social, economic and cultural status of their parents and the last ones have a strong influence in teenage.

\section{Graph 3}

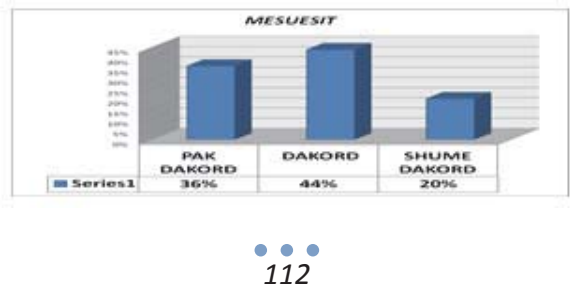


Data obtained by question 4 showed that $33 \%$ of students stated that parents have less capacity to this regard, $29 \%$ of them state that parents have sufficient capacity whilst $38 \%$ state that parents have too much capacity. These data show that not all parents collaborate with teachers and contribute for their children. Causes might be of different nature, either for negligence or for total lack or incapacity to engage because of economic, social and cultural reasons.

\section{Graph 4}

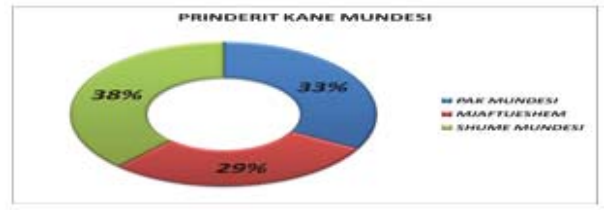

Responses to question 5 showed that $25 \%$ fairly agree, $42 \%$ of teachers agree and $33 \%$ of them strongly agree. This result makes us understand that in most cases it is the teachers who do not require collaboration with parents regarding effective teaching methods or the ways students are treated.

\section{Graph 5}

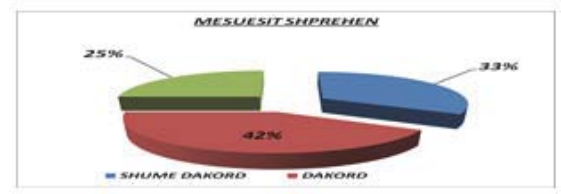

Regarding teacher-parents consultation sessions, data collected from questionnaires showed that $66 \%$ of teachers consider them as very important 30\% as important whereas $4 \%$ consider it as less important. These data also show that teachers feel that they should consult parents and students at least twice a year.

\section{Graph 6}

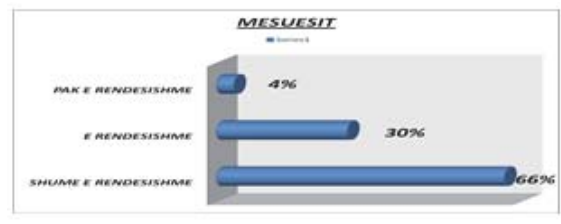

Regarding voluntarism of parents' involvement in the teaching-educating process it turned out that $79 \%$ of the teachers consider this element as very significant, $15 \%$ consider is as simply important and only $6 \%$ of them consider it as less important. These data reveal that most of the teachers are conscious that voluntarism of parents is very important and effecting not both in the teaching and learning processes.

\section{Graph 7}

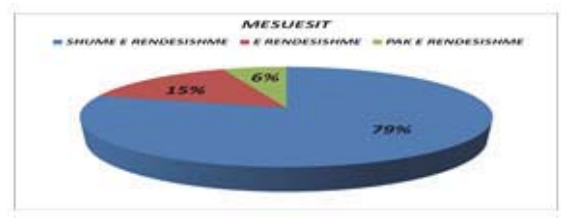




\section{Conclusions and Recommendations}

1. Teachers of the high school cycle consider participation of parents as very significant for the teaching and educating processes as well as for the students' academic achievements.

2. Parental involvement increases children's success at school, improves their habits and moral conduct, enhances caring for students and diminishes problems regarding students' behaviour and positively affects issues related to culture and behaviour at work.

3. Although the greatest part of the teachers accepts the significance and the need of parents' involvement in education, in everyday practices, there is a part of them who have not become aware of or do not consider this fact as significant.

4. Therefore, one of the strategies for increasing the effectiveness of parents' involvement in education has been and it will remain to be even in the future - qualification of teachers and students with the best and the most effective methods for positive results to this regard.

5. Teachers feel the need for consulting parents, at least twice a year, but they support increasing contacts and collaboration with them, too, in order to identify and discuss about both progress and failures as well as to increase effectiveness of their work with students.

6. Parents voluntarism remains a significant factor which should continuously be promoted and enhanced since it affects not only the teaching and learning process but even further.

\section{References}

Bandura, A, (1997). Self-efficacy: Toward a unifying theory of behavioral change.

Psychological Review. Stanford University, 84(2), 191-215.

Balli, S.J. (1996). "Family diversity and the nature of parental involvement". The Educational Forum, 60, 179-155.

Epstein, J.L (1986). "Parents 'reaction to teacher practies of parent involvement. Elementary School Journal, 86, 277-294.

Epstein, J.L,Salians,K.C.(1993). Reliabilities and summaries of scales: School and family partnership surveys of teachers and partners in elementary middle grades.

Baltimore, MD: Center on Families, Communities, Schools and Children's Learning and Center for Research on Effective Schooling for Disadvantaged Students, Johns Hopkins University.

Fan, X.\& Chen, M. (2001). "Parental Involvement and Student's Academic Achievement: A meta-analyssis". Educational Psychology Review, 13 (1), 1-22.

Hoover-Dempesy, K.V., Walker, J.M.T., Jones, K.P \& Reed, R.P.(2002). "Teachers Involving Parents ( TIP ): An in-service teacher education program for Enhancing parental involvement". Teaching and Teacher Education, 18 (7), 443-466

Karther,D. \& Lowden, F. (1997). "Fostering effective parent involvement" Contemporary Education, 69(1), 41-44. Study Report, UNICEF, March, 2008.

Trivette, K. \& Anderson, et al. (1995). "The effects of four components of parental involvement on eighth-grade student achievement : Structural analysis of NELS-88 data". School Psychology Review, 24, 299-317. 